\title{
Research for Modeling the Evolutionary Law of Mass Incidents on System Dynamics
}

\author{
Ding-Hua ZHANG ${ }^{1, a}$, Wei-Jun $\mathrm{LI}^{1, \mathrm{~b} \text {, * }}$ \\ ${ }^{1}$ School of Public Administration, South China University of Technology, Guangzhou, 510641, China \\ adhzhang@scut.edu.cn, bisukia@163.com \\ ${ }^{*}$ Corresponding author
}

Keywords: Mass incidents, SIR model, Related subjects, Key factors, System dynamics.

\begin{abstract}
This paper aims to establish an improved model of evolutionary law of mass incidents. Based on the SIR model, we propose mass incidents' three related subjects: public, government and third-party departments, and quantitatively analyze the key factors influencing these related subjects. Then, we build the mass incident model by the method of system dynamics. The evolution process of mass incidents will be captured by the simulation. The simulation is done by using Any Logic software, and the results show that the model is available and reflect the evolutionary law of mass incidents. It is useful to provide theoretical support for the emergency management and help government departments effectively prepare for and respond to mass incidents.
\end{abstract}

\section{Introduction}

According to the "Blue Book of China's Society" released by Chinese Academy of Social Sciences (CASS) in 2014[1], China's annual number of mass incidents is increasing up to tens of thousands and even involving millions of people. These mass incidents undermine the local normal order of production, resulting in the loss of people's lives and property.

Mass incidents originally appeared as a political term in official documents. It can be defined as a sudden outbreak because of the intermediation of some social events. However, due to the frequency, suddenness and uncertainty of the mass incident, it is difficult for government to control its process. Most experts are concentrated in theory and lack sufficient quantitative simulation experiments. Cheng-Lin Luo and Xiang-Yang Li[2] propose the seven main indexes of the evolution of mass emergencies. They point out the three main factor: the masses, government and media. In order to better embody the evolutionary law of mass incidents, the paper extracts three related subjects and builds a simulation model of mass incidents, based on SIR model and system dynamics.

\section{Summary of SIR model and system dynamics}

\section{SIR Model}

The SIR Model, originated by Kermack and McKendrick in 1927, is one of the most classic models in infectious diseases[3]. Not considering the impact of birth rate and death rate, the SIR Model divides the total population (depending on their disease status) into three compartments (Fig. 1).

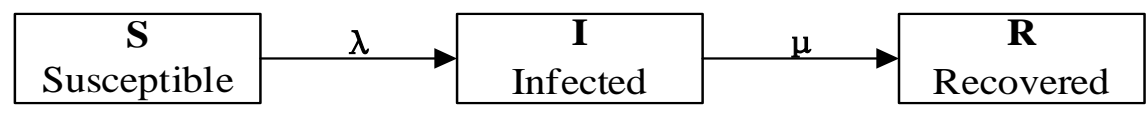

Fig. 1 SIR model

The main idea of the SIR model is to divide the population into several subdivisions, which represent different disease status, and then use the mathematical method to establish the dynamic equations of these variables, which can study the spreading dynamics of infectious diseases. So the model can be described by the following differential equations[4]: 


$$
\begin{gathered}
\frac{d S(t)}{d t}=-\frac{\lambda I(t)}{N} \cdot S(t) \\
\frac{d I(t)}{d t}=\frac{\lambda I(t)}{N} \cdot S(t)-\mu I(t) \\
\frac{d R(t)}{d t}=\mu I(t) \\
S(t)+I(t)+R(t)=N
\end{gathered}
$$

In these equations, $N$ represents the total population. $S(t) / I(t) / R(t)$ shows the quantity of the susceptible/infections/recovered population at $t$ moment. Those who transit to the infectious or recovered status per time step are affected by the infection rate $(\lambda)$ and recovery rate $(\mu)$. Besides, $S(t), I(t), R(t) \geq 0 ; N, \lambda, \mu>0$. It is found that the group behavior in the mass incident is extremely contagious, and its evolutionary process is very similar to the infectious disease process. So the SIR model is feasible in the study of mass incidents.

\section{System Dynamics}

System dynamics, which combines system theory, cybernetics and information theory, is a simulation technology developed by Professor J. W. Forrester from Massachusetts Institute of Technology (MIT) in the 1950s[5]. With the top-down reaction of complex behaviors is a method of describing the whole system by establishing system dynamics equation[6]. System dynamics, based on the relationship between the system behavior and the internal mechanism of a problem, expresses the relationship by mathematical modeling, and then factorizes the problem and analyzes the causality of variation.

\section{Relevant Subjects and Key Factors}

\section{Public}

\section{The Initial Proportion of Susceptible Status}

The initial proportion of susceptible status refers to the number of individuals in the susceptible status at the initial phase, affecting the trend of mass incidents. Different mass incidents have different initial proportions. The larger the proportion is, the more hazardous and drastic the mass incident is.

\section{The Way of Spreading Information}

There are a variety of ways to spread information in public.The paper proposes two main ways in mass incidents: oral communication and network communication. Oral communication refers to the individual spreading information by some face-to-face means, such as chat, speech and negotiation. Network communication refers to the individual spreading information by some online means, such as media and social network. Both of them can be measured by the number of contacts and the success rate of infection at a given time unit.

\section{The Average Recovery Time}

The average recovery time refers to the process that the public transits from susceptible status and action status to recovered status in the natural condition without any other external factors. We can use it to measure the periodicity and reflect the intensity of mass incidents. 


\section{Government}

\section{The Opening Information}

The government holds most of the important information of the whole society. Whether the information can be timely and accurately opened has decisive effect on the evolution of mass incidents.

\section{The Government Credibility}

The government credibility is a measure of government influence and appeal, reflecting the public's satisfaction and trust for the government. It indicates the public's trust in government disclosure and reflects the acceptance of information in mass incidents.

\section{The Ability of Digesting Information}

The ability of digesting information means that the public's understanding of the government's open information. It reflects the effectiveness of information disclosure in the government.

\section{Third-Party Department}

\section{The Third-Party Auxiliary}

The third-party auxiliary indicates the media's dissemination and interpretation of the government information. Its effects are divided into positive and negative, here mainly referring to the former. The auxiliary can be represented by the third-party auxiliary coefficient.

\section{The Ability of Controlling Information}

The ability of controlling information indicates that the third-party departments' ability of controlling false information in network, such as Weibo and WeChat. Whether the third-party can control the false information will directly relate to the evolution of mass incidents. The ability can be represented by the third-party controlling information coefficient.

\section{Simulation Model of Mass Incident}

Based on the SIR model, assuming that the total number of people in a region is $\mathrm{C}$, the public in the mass incident is divided into four categories: i. Normal status, representing that the people did not initially participate in the mass incident. ii. Potential status, representing the people affected by those in the Action status. iii. Action status, representing the people who participate in the mass incident and infect other people by spreading emotion and information. iv. Recover status, representing the people who have restored calm. So this paper builds a mass incident model (Fig. 2).

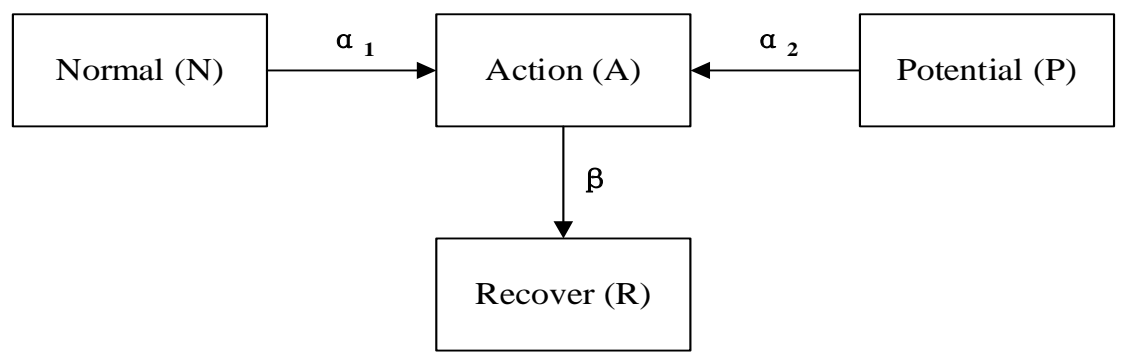

Fig. 2 Mass incident model based on SIR

Then the model is transformed into the following differential equation form:

$$
\begin{aligned}
& \frac{d N(t)}{d t}=\frac{-\alpha_{1} A(t)}{C} \cdot N(t) \\
& \frac{d P(t)}{d t}=\frac{-\alpha_{2} A(t)}{C} \cdot P(t)
\end{aligned}
$$




$$
\begin{gathered}
\frac{d A(t)}{d t}=\frac{\alpha_{1} A(t)}{C} \cdot N(t)+\frac{\alpha_{2} A(t)}{C} \cdot P(t)-\beta A(t) \\
\frac{d R(t)}{d t}=\beta A(t) \\
\alpha_{1}+\alpha_{2}=\alpha \\
N(t)+P(t)+A(t)+R(t)=C
\end{gathered}
$$

In these equations, $N(t)$ represents the quantity of the people in the Normal status at $t$ moment. $P(t)$ represents the quantity of the people in Potential status at $t$ moment. $A(t)$ represents the quantity of the people in Action status at $t$ moment. $R(t)$ represents the quantity of the people in Recover status at $t$ moment. Those who transit from Normal or Potential status to Action status per time step are affected by the infection rate $\left(\alpha_{1}\right.$ or $\left.\alpha_{2}\right)$. The recovery rate $(\beta)$ is affected by the key factors of the government and the third-party departments.

If $N(0)=N_{0}, P(0)=P_{0}, A(0)=A_{0}, R(0)=0, \lim _{t \rightarrow+\infty} N(t)=N_{\infty}, \lim _{t \rightarrow+\infty} P(t)=P_{\infty}, \lim _{t \rightarrow+\infty} A(t)=A_{\infty}$, $\lim _{t \rightarrow+\infty} R(t)=R_{\infty}$, eliminate $d t$, the equations can be merged into:

$$
A=\left(N_{0}+P_{0}+A_{0}\right)-(N+P)+\frac{\beta C}{\alpha} \ln \frac{N+P}{N_{0}+P_{0}}
$$

According to the model analyzing, this paper establishes a system dynamics simulation model of mass incidents (Fig. 3).

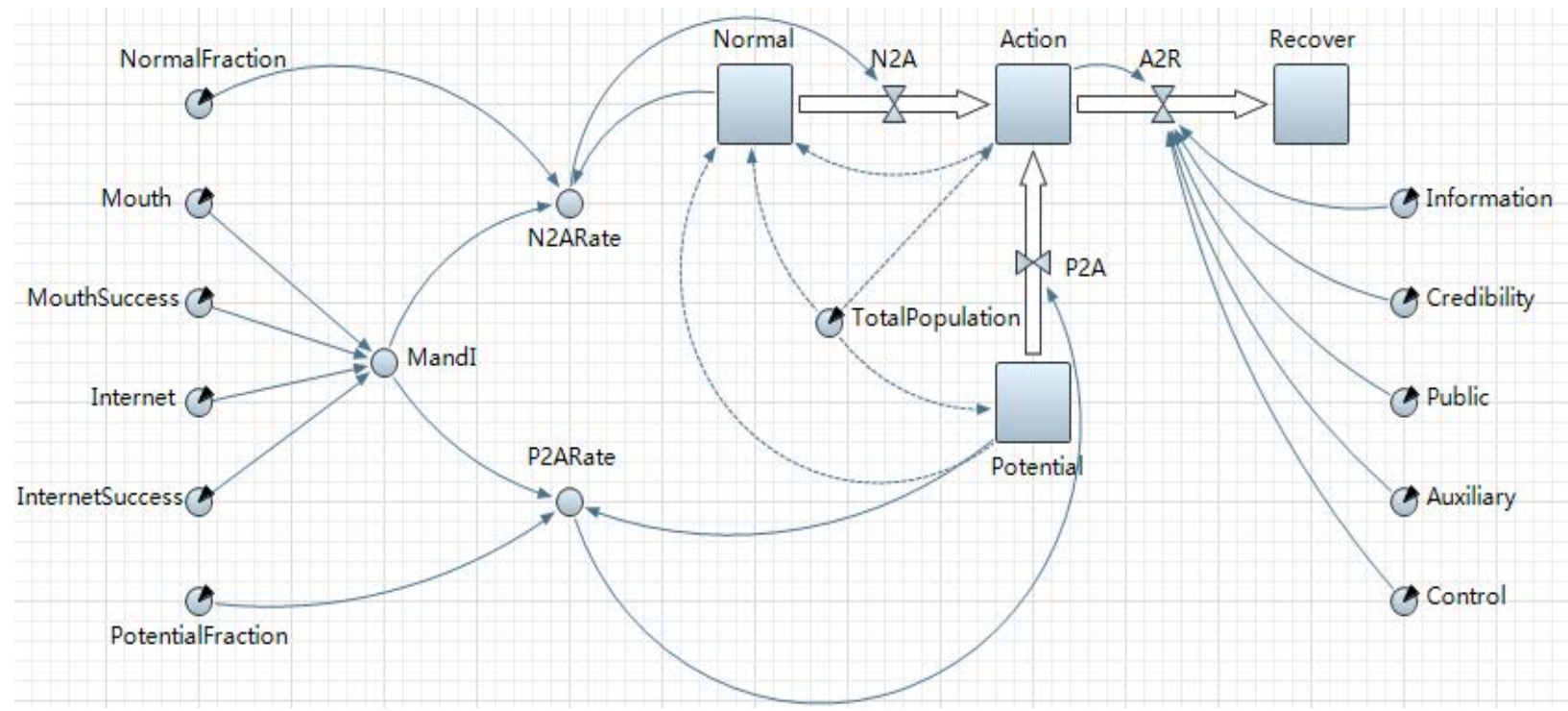

Fig. 3 System dynamics simulation model of mass incident

Generally, the evolution of the mass incident follows such process: transit from the Normal or Potential status to the Action status, and finally return to the Recover status.

\section{Result Analysis}

\section{The Impact of the Potential Status on the Evolutionary Law of Mass Incident}

Different mass incidents have different proportion of the people in Potential status. The proportions are adjusted respectively as follows (Fig. 4). It can be seen that the highest peak of the population in the Action status is positively correlated to the initial proportion of the people in the Potential status, that is, the higher the proportion is, the higher the participation and the greater the damage will be. 


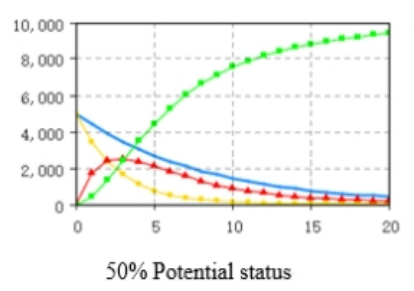

- Hormal people

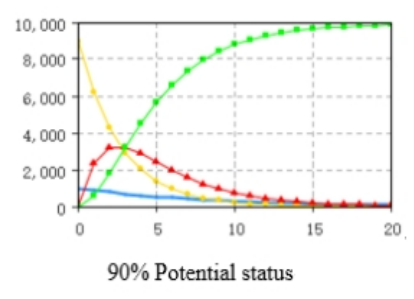

Potential peopl
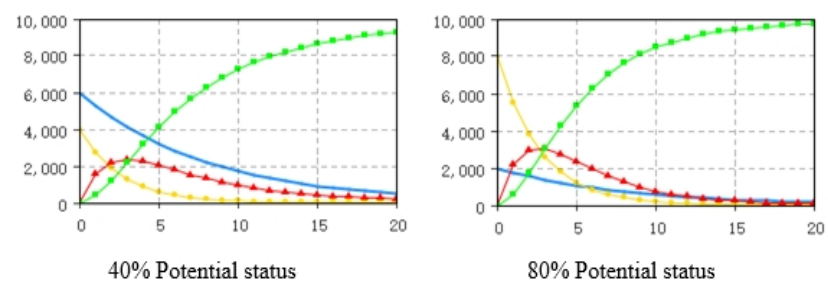

- Recover people

Fig. 4 Change in different status with different percentage of Potential status

\section{The Impact of Oral Communication and Network Communication on the Evolutionary Law} of Mass Incident

With a strong sense of trust, oral communication has higher transmission rate among friends, families and colleagues. Network communication has lower transmission rate because people usually question the information from the Internet. The parameters are adjusted as Table 1 shown.

Table 1 Parameters of oral communication and network communication

\begin{tabular}{|c|c|c|c|c|}
\hline $\begin{array}{c}\text { Experiment } \\
\text { group }\end{array}$ & $\begin{array}{c}\text { Contact of oral } \\
\text { communication } \\
\text { (person/day) }\end{array}$ & $\begin{array}{c}\text { Oral } \\
\text { communication } \\
\text { infection rate }\end{array}$ & $\begin{array}{c}\text { Contact of network } \\
\text { communication } \\
\text { (person/day) }\end{array}$ & $\begin{array}{c}\text { Network } \\
\text { communication } \\
\text { infection rate }\end{array}$ \\
\hline 1 & 10 & $10 \%$ & 100 & $2 \%$ \\
\hline 2 & 5 & $20 \%$ & 100 & $2 \%$ \\
\hline 3 & 5 & $10 \%$ & 200 & $2 \%$ \\
\hline 4 & 5 & $10 \%$ & 100 & $4 \%$ \\
\hline 5 & 10 & $20 \%$ & 100 & $2 \%$ \\
\hline 6 & 5 & $10 \%$ & 200 & $4 \%$ \\
\hline 7 & 10 & $20 \%$ & 200 & \\
\hline
\end{tabular}

The simulation results show that network communication has much more influence than oral communication in a mass incident (Fig. 5).Thus, it is suggested that the government strictly regulate the online information and the third-party filter false information as much as possible.
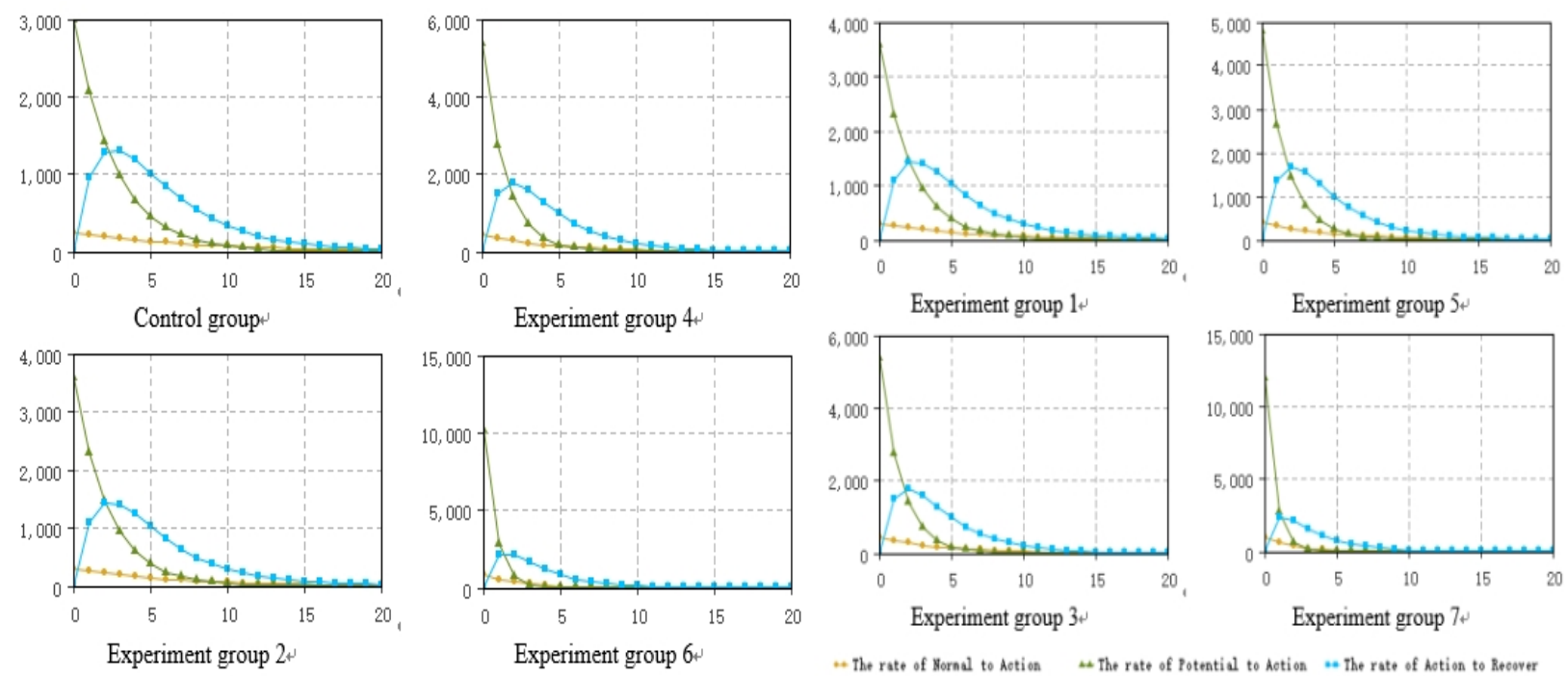

Fig.5 Status transition rate under different parameters of oral and network communication 


\section{The Impact of Government and Third-Party Departments on the Evolutionary Law of Mass Incidents}

This paper quantifies the mechanism of the government and the third-party departments. It explores the impact on the mass incident by changing the different values of the coefficients (Table 2).

Table 2 Information controlling capability coefficients of government and third-party departments

\begin{tabular}{|c|c|c|c|c|c|}
\hline $\begin{array}{c}\text { Experiment } \\
\text { group }\end{array}$ & $\begin{array}{c}\text { Government } \\
\text { opening } \\
\text { information } \\
\text { coefficient }\end{array}$ & $\begin{array}{c}\text { Government } \\
\text { credibility } \\
\text { coefficient }\end{array}$ & $\begin{array}{c}\text { Public } \\
\text { digesting } \\
\text { information } \\
\text { coefficient }\end{array}$ & $\begin{array}{c}\text { Third-party } \\
\text { auxiliary } \\
\text { coefficient }\end{array}$ & $\begin{array}{c}\text { Third-party } \\
\text { controlling } \\
\text { information } \\
\text { coefficient }\end{array}$ \\
\hline 1 & 0.4 & 0.2 & 0.2 & 0.2 & 0.2 \\
\hline 2 & 0.2 & 0.4 & 0.2 & 0.2 & 0.2 \\
\hline 3 & 0.2 & 0.2 & 0.4 & 0.2 & 0.2 \\
\hline 4 & 0.2 & 0.2 & 0.2 & 0.4 & 0.2 \\
\hline 5 & 0.2 & 0.2 & 0.2 & 0.2 & 0.4 \\
\hline 6 & 0.4 & 0.4 & 0.4 & 0.2 & 0.2 \\
\hline 7 & 0.2 & 0.2 & 0.2 & 0.4 & 0.4 \\
\hline 8 & 0.4 & 0.4 & 0.4 & 0.4 & 0.4 \\
\hline
\end{tabular}

The simulation results show that the information controlling ability of the government and the third-party departments has significant effect on mass incidents (Table 3).

Table 3 Analysis of the impact of government and third-party departments on the mass incident

\begin{tabular}{|c|c|c|c|c|}
\hline $\begin{array}{c}\text { Experiment } \\
\text { group }\end{array}$ & $\begin{array}{c}\text { Mass incident } \\
\text { starting time }\end{array}$ & $\begin{array}{c}\text { Mass incident } \\
\text { peak time }\end{array}$ & $\begin{array}{c}\text { Mass incident } \\
\text { ending time }\end{array}$ & $\begin{array}{c}\text { Peak proportion of } \\
\text { total population }\end{array}$ \\
\hline 1 & 16 & 37 & 75 & $49 \%$ \\
\hline 2 & 18 & 42 & 78 & $48 \%$ \\
\hline 3 & 17 & 40 & 76 & $47 \%$ \\
\hline 4 & 20 & 43 & 80 & $39 \%$ \\
\hline 5 & 18 & 41 & 78 & $38 \%$ \\
\hline 6 & 16 & 40 & 75 & $30 \%$ \\
\hline 7 & 20 & 46 & 80 & $13 \%$ \\
\hline 8 & 30 & 60 & 95 & $5 \%$ \\
\hline
\end{tabular}

\section{Conclusions}

This paper focuses on an simulation model on the evolutionary law of mass incidents, based on system dynamics and SIR model. A large number of simulation experiments have been done. And the results show that the mass incident model is reasonable and it can make the evolution of mass incidents more believable.In a future work,we are interested in building the hybrid simulation model based on system dynamics and multi agent system.

\section{Reference}

[1] Chinese Academy of Social Sciences. 2014 Blue Book of China’s Society[M]. Beijing: Social Science Academic Press, 2013. (In Chinese)

[2] Chenglin Luo, Xiangyang Li. Analysis on Mass Emergency and Its Evolutive Mechanism[J]. China Soft Science, 2009(6): 163-171.(In Chinese)

[3] Kermack WO, McKendrick AG. A contribution to the mathematical theory of epidemics[C]. Proceedings of the Royal Society 115 A, 1927(772): 700-721. 
[4] Ronggui Luo, Tao Jiang. Research on Diffusion Model Based on SIR Infectious Disease Model[J]. Journal of Industrial Engineering and Engineering Management, 2006, 20(1):32-35.(In Chinese)

[5] Forrester J W. Industrial dynamics: A breakthrough for decision makers[J]. Harvard Business Review, 1958, 36(4): 37-66.

[6] Ronghu Chen. Constructing System Dynamics Based Hybrid Simulations[J]. Journal of System Simulation, 2009, 21(4): 932-935.(In Chinese) 